\title{
AS CRÍTICAS DE HENRI BERGSON E DE MAURICE MERLEAU-PONTY AOS ENFOQUES MATERIALISTAS DO PROBLEMA CORPO-MENTE
}

\section{Danilo Saretta Verissimo Reinaldo Furlan}

Resumo: Neste artigo, apresentamos as críticas de Henri Bergson e de Maurice Merleau-Ponty aos enfoques materialistas do problema corpo-mente. Tais enfoques são intrinsecamente ligados às ambições científicas, inauguradas com a modernidade, de totalizar os fenômenos que nos circundam e de unificar a diversidade do mundo através de um único padrão explicativo.Bergson,em uma espécie de fenomenologia do ato perceptivo, buscou suplantar as teses materialistas da relação entre mente e cérebro. Atendo-se ao paralelismo psicofisiológico, mostrou que a percepção atende às necessidades do ser vivo. Além disso, abordou a relação entre memória e cérebro, combatendo a ideia de que as recordações possuam uma tal natureza que permita que elas sejam armazenadas na massa cerebral.Já Merleau-Ponty, n'A Estrutura do Comportamento, após realizar a crítica das concepções clássicas do funcionamento nervoso e depois de se apropriar dos resultados de pesquisas que apresentam o cérebro enquanto entidade coordenadora da estrutura do comportamento, apresenta uma visão do funcionamento nervoso apoiada no primado do mundo percebido a partir da noção de forma. Discutimos, ainda, as heranças filosóficas legadas por Bergson a Merleau-Ponty e algumas críticas deste à obra do seu antecessor.

Palavras-chave: Problema corpo-mente. Paralelismo psicofisiológico. Bergson, Henri Louis, 18591941. Merleau-Ponty, Maurice, 1908-1961.

\section{Introdução}

O problema mente-corpo, com suas diversas variedades, permanece vivo e causando embaraços a neurocientistas, psicólogos, filósofos, linguistas e cientistas da 
computação, fato que justifica estudos histórico-filosóficos que retomem a questão e os encaminhamentos que lhe foram dados por pensadores cujo alcance das suas reflexões é inquestionável.

Esse é o caso de Bergson e Merleau-Ponty. Esses dois autores possuem confluências significativas no que tange à pesquisa filosófica e à contribuição que suas obras representam para a epistemologia da psicologia, das neurociências e da biologia. Trata-se de dois filósofos franceses de gerações consecutivas e que se preocuparam, ao longo de suas obras, com a superação das antinomias geradas pelo pensamento cartesiano na filosofia e nas ciências. Ademais, ambos desenvolveram uma mesma atitude na pesquisa filosófica: a de buscar nas ciências, sobretudo naquelas anteriormente mencionadas, os fatos sobre os quais organizaram e elaboraram o seu pensamento. Os trabalhos desses dois pensadores remetemnos diretamente às psicologias e ciências do funcionamento nervoso do século XIX e do início do século XX, constituindo, ao mesmo tempo, um precioso retrato e uma inestimável crítica do pensamento científico daquele período.

\section{Os termos do problema}

Bergson (1974a, 1974b) atém-se ao paralelismo psicofisiológico, cuja tese, segundo ele, é de que há equivalência entre o estado psíquico e o estado cerebral. $O$ autor estabelece os axiomas do paralelismo nos seguintes termos:

Sendo dado um estado cerebral, segue-se um estado psíquico determinado". Ou ainda: "Uma inteligência sobre-humana, que assistisse ao movimento dos átomos de que é feito o cérebro humano e que tivesse a chave da psicofisiologia, poderia ler, num cérebro trabalhando, tudo o que se passa na consciência correspondente.' Ou enfim: 'A consciência não diz nada mais do que se passa no cérebro; ela apenas o exprime numa outra língua. (Bergson, 1974a, p.49)

Para Bergson, no interior dessa questão, destacam-se as correntes que buscam assimilar o mental ao físico. Nessa perspectiva, a consciência surge como uma duplicação casual do estado cerebral, como uma "fosforescência" acrescentada ao jogo de moléculas na substância cerebral e que, iluminando a si mesma, engendraria a ilusão de agenciar alguma vontade própria.

Bergson é peremptório ao afirmar a fonte metafísica, e não científica, da tese paralelista. Segundo ele, suas origens remontam à filosofia de Descartes, que postulou um dualismo de substâncias. Espírito e matéria, apesar de unirem-se estreitamente, o fazem de um modo difícil de conceber, visto que configuram substâncias radicalmente diferentes. $O$ espírito é inextenso e indivisível, um sopro que anima o organismo e que sente o mundo 
por intermédio dos órgãos exteriores e interiores do aparelho nervoso. Além disso, o espírito é uma substância pensante. (Descartes, 1636/1992, 1641/1992). A matéria e o corpo são, por outro lado, substâncias extensas e, por isso, podemos tocá-los, examiná-los, dissecá-los e observá-los em funcionamento.

No tocante à tese paralelista, Bergson entreviu uma simplificação progressiva da metafísica cartesiana que culminou, justamente, na expressão do materialismo na ciência do século XIX. De fato, a experiência revelanos uma solidariedade entre o corpo e a vida da consciência. Essa relação deveria ser abordada, na visão de Bergson, por um contínuo movimento de ida e volta entre o que ele chamou de método de observação interior, preconizado especialmente ao filósofo, e os fatos expostos pela psicologia e pela patologia, movimento esse que traria a possibilidade de obtenção de um saber cada vez mais aperfeiçoado sobre a relação entre corpo e consciência. Mas, completa Bergson,"(1974b) o metafísico não desce facilmente das alturas" (p.93), ele frequenta com mais satisfação e segurança o plano dos puros conceitos e, por isso, não pôde jamais oferecer à ciência uma filosofia que, baseada nos fatos conhecidos, iluminasse a sua prática. Houve espaço, então, para que a hipótese paralelista fosse deduzida dos princípios básicos de uma metafísica que sustentava as esperanças da física moderna, cujos representantes reduziam os problemas astronômicos e físicos a problemas de mecânica. O universo material, em seu todo, concebido como uma imensa máquina, poderia ser submetido às leis matemáticas. Os corpos em geral, e o corpo humano em particular, representavam engrenagens cujas ações poderiam ser matematicamente calculadas. Quanto à alma humana, seria, principalmente, a tradução daquilo que o corpo exprimia em extensão e movimento. Quanto mais estreita ia se tornando esta metafísica, mais ela se infiltrava na fisiologia. Estava aberto, então, o caminho para que se afirmasse a primazia do cérebro na experiência humana. Afinal, o fisiologista, desamparado pelo pensamento filosófico, e que possuía recursos apenas para compreender o cérebro, procedeu como se o pensamento fosse simplesmente uma função daquele. Em suma, na falta de uma teoria filosófica flexível acerca da dupla experiência do interior e do exterior, a ciência do século XIX aceitou uma doutrina adequada aos métodos e objetivos que julgava vantajosos (Bergson, 1974b).

Estamos tratando, portanto, da pretensão da ciência de conhecer cada passo da "dança de moléculas, átomos e elétrons de que é feita a substância cerebral" (Bergson, 1974b, p. 91) e de elaborar uma espécie de dicionário que correlacione cada movimento cerebral à linguagem da razão e da emoção. Assim, a consciência, com todas as suas manifestações, não passando de um efeito, seria conhecida em suas bases causais. Diz Bergson (1974a): "Quanto mais a ciência aprofunda na natureza do corpo em direção à sua 'realidade', tanto mais ela reduz cada propriedade deste cor- 
po e, consequentemente, sua própria existência, às reações que ele mantém com o restante da matéria capaz de influenciá-lo" (p.54).

\section{A desconstrução do materialismo em Bergson}

Voltando-nos, propriamente, para a abordagem bergsoniana das teses materialistas no que tange ao problema mente-corpo, notamos que é na crítica à noção de percepção nelas presente que o filósofo encontra os instrumentos para a sua desconstrução. No materialismo, os acontecimentos cerebrais são suficientes para explicar a percepção do mundo e, por isso, são concebidos de modo quase isolado dele. Desse modo, a percepção é reduzida à tradução do que ocorre no sistema nervoso. Mas, Bergson demonstra, com clareza, que recaímos em uma contradição se fazemos do cérebro a condição da imagem total', visto que ele, em hipótese, é uma parte dessa imagem. Se a representação do universo material vem dos movimentos moleculares cerebrais, o universo deverá ser tomado por uma representação do todo nascida do que seria apenas uma parte desse mesmo todo. Então, uma pequena parte da imagem do todo estaria gerando a imagem total?

Em seu retorno à percepção, motivado pelo intuito de combater tanto o realismo quanto o idealismo, Bergson deu crédito aos seus aspectos fenomenais e, assim, a base orgânica do fenômeno perceptivo foi colocada em outro ponto de referência. O filósofo reconhece, sem dúvida, a sustentação material exercida pelos elementos do sistema nervoso, mas deseja destacar que a percepção, em seu conjunto, possui sua razão de ser na tendência do corpo a se mover, na sua tendência de responder aos interesses e necessidades do ser vivo. À semelhança do que será defendido por Merleau-Ponty em “A Estrutura do Comportamento" (1942 / 2002), Bergson observou uma indeterminação implicada na estrutura do sistema nervoso. Para ele, os tecidos nervosos parecem ter sido construídos antes em função dessa indeterminação do que da própria representação. E é esse indeterminado que sinaliza a necessidade de se conceber a percepção enquanto "... relação variável entre o ser vivo e as influências mais ou menos distintas dos objetos que lhe interessam" (Bergson, 1968, p. 29). Atento em questionar a percepção do modo como aparece a si mesma, e não dentro dos quadros do realismo, projeto que Merleau-Ponty (2000) classificaria como uma espécie de fenomenologia, Bergson apresenta-a como um processo no qual o mundo solicita do corpo ações que expressam um dis-

1 Sobre a noção de imagem em Bergson: "A matéria, para nós, é um conjunto de 'imagens'. $E$ por 'imagem' entendemos uma certa existência que é mais do que aquilo que o idealista chama uma representação, mas menos do que aquilo que o realista chama uma coisa, - uma existência situada a meio caminho entre a 'coisa' e a'representação'. Esta concepção da matéria é simplesmente aquela do senso comum... Pois, para o senso comum, o objeto existe nele mesmo e, de outra parte, o objeto é, nele mesmo, pitoresco como nós o percebemos: é uma imagem, mas uma imagem que existe em si" (Bergson, 1968, pp.1-2). 
cernimento prático voltado para a manutenção e desenvolvimento do ser vivo. No quadro de referência cujo relevo fica por conta dos seus aspectos fenomenais, a percepção deixa de poder ser reduzida a uma tradução dos movimentos moleculares cerebrais, e a tese materialista da relação entre o corpo e a mente perde sua razão de ser $^{2}$.

A crítica ao materialismo também se faz presente nas análises de Bergson sobre as relações entre memória e cérebro. Discutindo o processo de reconhecimento de imagens, sobretudo com base em casos de lesão cerebral que perturbam esse processo, o autor combate a idéia de que as recordações possuam uma tal natureza que permita que elas sejam armazenadas na massa cerebral. A questão que parece dirigir o filósofo na sua argumentação é a seguinte: em que sentido uma lesão cerebral pode atingir a memória? A hipótese bergsoniana é que as recordações ligam-se aos movimentos que esboçam uma ação nascente e que são esses movimentos que podem ser atingidos no caso de uma lesão cerebral e não as recordações propriamente ditas.

Segundo Bergson, para que o processo pelo qual reconhecemos algo seja estudado adequadamente, é necessário que as recordações sejam dissociadas em dois elementos: a imagem-recordação e o movimento. Com efeito, o ato de reconhecimento envolveria, inicialmente, um processo motor seguido da projeção das recordações sobre as atitudes correspondentes. É uma visão mista da recordação que leva a dificuldades na compreensão do ato de reconhecimento. Nessa perspectiva, o fenômeno da recordação permanece composto, de um lado, por uma carga de hábito motor e, de outro, por uma imagem mais ou menos conscientemente localizada. Com a pretensão de simplificar o fenômeno, dando-lhe inteligibilidade, o mecanismo cerebral que sustenta o hábito motor será identificado, também, como o substrato da imagem consciente. “De onde a estranha hipótese de recordações armazenadas no cérebro, que se tornariam conscientes por um verdadeiro milagre, e nos reenviariam ao passado por um processo misterioso" (Bergson, 1968, p. 95). As teorias do reconhecimento acabam, portanto, em hipóteses fisiológicas em que o cérebro é concebido como um armazém de ideias. $O$ reconhecimento se daria por traços cerebrais semelhantes ou pela comunicação das células de percepção com as células que guardam as recordações.

2 Sobre a relação entre a análise bergsoniana da percepção e a fenomenologia, Pinto (2006) comenta:"Bergson redefine a percepção como ação no mundo e repõe a unidade primordial entre mundo e corpo próprio, unidade recuperada pelo encontro com o fundo de intuição real sobre o qual a inserção pragmática se dá, fundo que explicita um domínio pré-objetivo como relação entre imagens, como imagens em movimento. Nessa medida, ele estaria oferecendo uma alternativa igualmente perscrutada pela fenomenologia, já que circunscrever a percepção como ação no mundo efetivada por uma imagem especial significa vincular internamente percepção e vida, o perceber passa a ser considerado um processo vital e suas conseqüências são retomadas enquanto determinações de um mundo antes de mais nada vivido" (p. 175). 
Nessa direção, entende-se que lesões cerebrais possam destruir as recordações, como se as representações auditivas, por exemplo, permanecessem adormecidas no córtex sob a forma de modificações físico-químicas das células nervosas. Tais representações, despertadas por vibrações vindas do exterior, encontrariam representações complementares, que evocariam as idéias. Mas, um cérebro que não registra senão a materialidade dos sons percebidos, o que faz das recordações coisas inertes e passivas, deveria armazenar incontáveis imagens da mesma palavra, levando-se em conta que as palavras são pronunciadas por vozes diferentes, com timbres e volumes diferentes e, no mais das vezes, com acentuações distintas. Além disso, conceder individualidade às palavras constitui uma abstração. Não aprendemos a pronunciar palavras, mas frases. A palavra se insere na"fisionomia" e no "movimento" da frase, encontra o seu sentido no todo do que está sendo dito."Onde está, com efeito, a medida comum, onde está o ponto de contato entre a imagem seca, inerte, isolada, e a realidade viva da palavra que se organiza com a frase?" pergunta Bergson (1968, p.131). A menos que todos os homens tivessem vozes idênticas, não há como imaginar que as palavras ouvidas possam unir-se a suas imagens no córtex cerebral. Além do mais, se fosse verdade que as recordações são armazenadas nas células corticais, observaríamos, nas afasias sensoriais, a perda irreparável de algumas palavras, argumenta o filósofo. Mas, isso não é o que se verifica nos estudos clínicos. Outro ponto de apoio à tese de Bergson são os casos em que a amnésia segue uma marcha "metódica": atinge primeiramente os nomes próprios até chegar aos verbos. Se considerarmos as imagens verbais armazenadas nas células nervosas, devemos considerar, também, que a doença ataca as células sempre numa mesma ordem. Isso é possível? Para Bergson, a questão se esclarece se admitimos que as recordações têm necessidade de um adjuvante motor para se atualizar, que a atitude mental se insere numa atitude corporal. Ora, os verbos exprimem, essencialmente, as ações. Assim, quando a linguagem ameaça nos deixar, um esforço corporal é capaz de resgatá-la. Já os nomes próprios estão, efetivamente, distantes das ações do nosso corpo, sendo, assim, atingidos em primeiro lugar nas perturbações progressivas da linguagem.

Toda percepção nasce das vibrações transmitidas pelos nervos aos centros perceptivos. Se essa propagação é a origem das imagens nos centros corticais, pode-se afirmar que a memória é uma função do cérebro. Assim, perturbações na memória seriam explicadas por lesões cerebrais que atingem, exatamente, as regiões ocupadas pelas recordações. Mas, movimento não produz senão movimento, diz Bergson. As vibrações perceptivas imprimem no corpo uma atitude na qual as recordações se inserem, sendo selecionadas, conforme dissemos, segundo o ponto de vista prático ou vital, que representa a situação do corpo no mundo. Em si mesmas, as recordações devem ser procuradas alhures. Nessa perspectiva, as lesões cerebrais atingem somente as ações nascentes. $O$ corpo é impedido de esbo- 
çar a atitude adequada frente a um objeto e a recordação, por conseguinte, é impedida de se atualizar, uma vez que a percepção tem, em primeiro lugar, uma função eminentemente prática. O que significa, portanto, que a lesão cerebral não destrói as recordações. Dessa forma, Bergson contorna, ao mesmo tempo, os embaraços provenientes da tese do armazenamento das recordações no cérebro, e, de modo mais geral ou fundamental, os decorrentes da consideração de uma imagem em particular, por exemplo, essa que temos do cérebro como representante do campo das imagens, do qual, na verdade, faz parte, e que chamamos de campo fenomenal.

\section{Heranças filosóficas}

Conforme afirmação anterior, a obra de Bergson foi marcante na herança filosófica recebida por Merleau-Ponty. Tal herança distingue-se por duas características principais. Primeiramente, a preocupação com a superação dos embaraços teóricos do dualismo cartesiano, e aqui invocamos as palavras iniciais de Bergson (1968) em Matéria e Memória:

Este livro afirma a realidade do espírito, a realidade da matéria, e tenta determinar a ligação de um ao outro a partir de um exemplo preciso, o da memória. Ele é portanto claramente dualista. Mas, de outra parte, ele visa corpo e espírito de maneira tal que ele espera atenuar bastante, senão suprimir, as dificuldades teóricas que o dualismo sempre suscitou e que fazem com que, sugerido pela consciência imediata, adotado pelo senso comum, ele seja pouco estimado entre os filósofos. (p. 1)

A segunda característica é um método de reflexão psicológica tendendo a uma metafísica da natureza. Merleau-Ponty buscou, claramente, um deslocamento em relação a esse segundo ponto (Bimbenet, 2004). Com efeito, Bergson foi o último filósofo de uma tradição espiritualista que buscava, em uma metafísica, a conciliação entre natureza e espírito. Segundo Bimbenet (2004),

Merleau-Ponty não cessa de se diferenciar de seu primogênito nos seus primeiros trabalhos, mas pensamos que é preciso compreender essas tomadas de distância inicialmente sobre o fundo de um projeto comum, de pensar o humano sem restrição, e ao mesmo tempo sem redução, a partir da vida (p. 29, itálicos nossos)

Merleau-Ponty vê no pensamento de Bergson, assim como na filosofia husserliana, um significativo ensaio de retorno às coisas (Barbaras, 1999, citado por Pinto, 2006). Mas, para Merleau-Ponty, noções bergsonianas como as de ação e de imagens-recordações não alteraram significativamente a psicologia da percepção. De um modo geral, sua opinião é de que 
a filosofia não possui noções de consciência e de ação que possibilitem uma verdadeira comunicação interior entre elas. A consciência enquanto duração ou enquanto berço de julgamentos permanece sem estrutura e sem natureza. A ação, enquanto expressão natural pura, permanece uma série de eventos exteriores uns aos outros. Consciência e ação, concebidos dessa maneira, estão justapostos e não unidos. A ação a que Bergson se refere é sempre uma ação vital, destinada à manutenção da existência. Assim, os atos propriamente humanos, como o de falar, de vestir-se, de trabalhar, permanecem destituídos de um sentido próprio, além daquele reservado pela biologia ${ }^{3}$. Além disso, a ação, em Bergson, parece, no mais das vezes, reduzida a uma noção motora ${ }^{4}$. Quanto às imagens-recordações, não se pode afirmar que escapam ao tratamento dado a uma espécie de objeto mental, igual a tantos outros criados no âmbito da psicologia. Bergson, envolvido em um esforço para se desvencilhar das concepções materialistas presentes no problema mente-cérebro, parece não ter se afastado de um realismo mentalista. Cabe voltarmo-nos às palavras de Merleau- Ponty (1942/2002):

A negação do realismo materialista não parece possível senão em benefício do realismo mentalista e inversamente. Não se vê que a partir do momento em que o comportamento é tomado "em sua unidade" e no seu sentido humano, não se trata mais de uma realidade material e tampouco, de outra parte, de uma realidade psíquica, mas de um conjunto significativo ou de uma estrutura que não pertence propriamente nem ao mundo exterior, nem à vida interior. É o realismo em geral que seria preciso pôr em causa. (p. 197)

Apesar das diferenças filosóficas, que, em realidade, sugerem um avanço no processo reflexivo, Merleau-Ponty, da mesma forma que Bergson, não hesitava em "entrar em contato com os fatos". Sua atitude não era a do metafísico que, conforme os dizeres de Bergson (1974a), acreditaria "sujar as mãos" caso entrasse em contato com os dados referentes às patologias mentais, por exemplo. Tudo nos faz crer que Merleau-Ponty herdara de seu antecessor a ideia de que o pensamento filosófico, sobretudo aquele que se instala no campo de uma pretensa natureza humana, não pode

3 "como se a consciência não pudesse ultrapassar as melodias do instinto sem se liberar de toda forma determinada", quando se trata, justamente, de "descrever as estruturas de ação e de conhecimento nas quais ela se engaja" (Merleau-Ponty, 1942 / 2002, p.178).

4 A respeito do vínculo entre consciência e motricidade na filosofia de Merleau-Ponty, Furlan (2006) comenta:"a consciência é um 'eu posso', e não um 'eu penso', e toda percepção revela determinada postura do corpo no mundo enquanto um campo de ação efetiva e / ou virtual. Por isso a motricidade se revela desde o princípio de fundamental importância para a descrição do sentido do mundo e da encarnação da consciência, importância que a uma só vez lembra a crítica de Bergson à concepção abstrata da percepção enquanto contemplação - quando ela é eminentemente vital ou devotada à ação -, e a insuficiência de sua filosofia nessa direção, pois nela ainda se trata, segundo Merleau-Ponty, de entender a percepção como a consciência dos movimentos nascentes no próprio corpo, o que configuraria novamente a separação entre o automatismo desses movimentos e a sua consciência, quando se trata de perceber a própria motricidade como um modo de ser consciência." (pp. 48-49). 
prescindir dos fatos apresentados pelas ciências tais como a psicologia, a patologia e a fisiologia. Com efeito, já em seu primeiro trabalho, A Estrutura do Comportamento (1942/2002), Merleau-Ponty debruçou-se sobre os conhecimentos que vinham sendo produzidos, sobretudo, na psicologia e na neurofisiologia. Com o intuito de aproximar-se do problema das relações entre consciência e natureza, neste livro optou por partir "de baixo", da análise do comportamento desde suas bases orgânicas. A partir daqui, focalizaremos alguns argumentos, presentes nessa obra, que podem ser significativos para a discussão que ora nos ocupa.

\section{Campo fenomenal e funcionamento nervoso}

Merleau-Ponty, após realizar a crítica das concepções clássicas do funcionamento nervoso, bem representadas na reflexologia de Pavlov, e depois de se apropriar dos resultados de pesquisas mais modernas cuja essência é apresentar o cérebro enquanto entidade funcional e coordenadora da atividade que sustenta a estrutura do comportamento, logra alcançar uma visão do funcionamento nervoso apoiada no primado do mundo percebido a partir da noção de forma.

Contra o "espírito anatômico", que faz do funcionamento nervoso uma atividade fundada em conexões visíveis e territórios bem demarcados, elevaram-se resultados de pesquisas que se destacaram pela ambição de realizar uma descrição concreta dos fenômenos observados, ou seja, sem isolá-los do seu contexto, e pela realização de análises diametralmente opostas às análises que fragmentam os fenômenos em partes reais externas umas às outras.

De fato, um novo gênero de análise se impõe. As lesões corticais não podem ser consideradas como perturbações eletivas, que dizem respeito apenas a fragmentos do comportamento. Retornando aos fenômenos, vemos que a transformação patológica acarreta um comportamento menos organizado, mais amorfo e que permanece impermeável a um olhar que nele busque isolar elementos ou conteúdos. O comportamento normal ou patológico exige uma análise que se paute não na observação enquanto simples notação das diferenças, mas na compreensão, buscando a "fisionomia de um conjunto" irredutível às suas partes e buscando a sua lei imanente. Dessa forma, a doença deixa de ser algo que apenas produz efeitos e pode passar a ser considerada como uma nova significação do comportamento.

Disso advêm conclusões sobre o "setor central" da atividade nervosa. "A existência de perturbações de estrutura sugere a de uma função geral de organização do comportamento. Esta função deveria caracterizar a região central do córtex", diz Merleau-Ponty (1942/2002, p. 74), referindo-se às conclusões de autores como Buytendijk, Piéron e Goldstein. Assim, o cé- 
rebro deixa de ser considerado sede de inúmeros dispositivos anatômicos para ocupar a posição de um sistema regulador, capaz de garantir ao comportamento as suas características gerais.

Com isso, estes autores não pensam em dizer que as funções cerebrais são indiferentes ao substrato pelo qual se realizam. De fato, o local das lesões é o ponto principal das perturbações de estrutura e determina a sua distribuição preferencial. Sabemos, por exemplo, que a destruição de uma área especializada do córtex cerebral leva a substituições funcionais, mas que estas nunca restituem plenamente a função afetada. Por outro lado, a especialização das regiões cerebrais não suprime a sua relação com o conjunto do funcionamento nervoso. Assim é que lesões occipitais levam a perturbações no pensamento visual, não porque as áreas occipitais sejam a sede deste modo de pensamento, mas porque são "os meios privilegiados de sua realização" (Merleau-Ponty, 1942/2002, p. 79), segundo as indicações de Piéron. Em outros termos, a relação entre a função e o substrato é de reciprocidade. Qualquer território da massa cerebral está ligado ao funcionamento global do sistema nervoso e, de modo análogo, o funcionamento nervoso não deixará de ser profundamente alterado se houver uma alteração em qualquer um desses territórios. Os comportamentos superiores estão ligados ao cérebro enquanto entidade funcional, sustentada por centros coordenadores cuja atividade concerne à estrutura, organização e configuração dos comportamentos. Estes centros possuem por função improvisar a todo instante as coordenações necessárias para que sejam elaboradas as propriedades estruturais da linguagem, por exemplo. A flexibilidade é uma marca deste processo."Se o centro coordenador, no lugar de realizar as coordenações de fonemas possui nele próprio tantos dispositivos reguladores quanto há de palavras, não se vê mais o que os distingue de 'traços cerebrais'"' (Merleau-Ponty, 1942/2002, p. 95). Neste caso, não se ultrapassa os hábitos do antigo paralelismo, que encontra no mapa cerebral relações de semelhança entre as palavras, por exemplo. Em qualquer forma de percepção - visual, espacial, de linguagem -, o funcionamento nervoso não implica o desencadeamento de dispositivos preestabelecidos. O processo fisiológico "deve ser improvisado, constituído ativamente no momento mesmo da percepção" (p. 97).

Diante do exposto, conclui-se que uma concepção funcional do paralelismo é o máximo que se pode aceitar. Segundo Merleau-Ponty, a antiga fisiologia não errou ao colocar em paralelo a atividade nervosa e as operações da consciência. Contudo, ao se valer do método de análise elementar, alcançou tão somente um paralelismo ilusório, no qual se dissociava o funcionamento nervoso em uma série de processos justapostos, reduzindo, por outro lado, os atos de consciência à associação de conteúdos reais. Com o descrédito da análise elementar na psicologia e na fisiologia, passou-se do paralelismo de elementos a um paralelismo funcional ou estrutural, em que os fatos psíquicos não são mais justapostos aos fatos 
fisiológicos, em que a psicologia e a fisiologia procuram os modos de organização do comportamento, "uma para descrevê-los, a outra para determinar-lhes o suporte corporal" (Merleau-Ponty, 1942 / 2002, p.84).

Qual é, então, o significado do substrato somático na estrutura do comportamento? De fato, se tomarmos o cérebro por uma massa de células e de condutores, diz Merleau-Ponty, e o espaço por uma multiplicidade de partes exteriores umas às outras, será preciso dizer que os comportamentos superiores não estão contidos nem no cérebro nem no espaço, visto que a realidade fisiológica cerebral não é representável nos parâmetros do pensamento real. Em se tratando da relação entre a percepção e o cérebro, deve-se, portanto, admitir que os eventos nervosos constituem a condição de existência do fenômeno perceptivo, contudo deve-se admitir, também, que eles não dão conta daquilo que percebemos. Merleau-Ponty (1942/2002) diz:

A passagem do influxo nervoso em tais condutores não produz o espetáculo visível, ela nem mesmo determina-lhe a estrutura de modo unívoco, visto que esta se organiza segundo leis de equilíbrio que não são nem aquelas de um sistema físico, nem aquelas do corpo considerado como tal.O substrato somático é o ponto de passagem, o ponto de apoio de uma dialética. (p. 222)

Dialética que se estabelece entre o organismo e o mundo percebido, e que revela o lugar do comportamento propriamente dito enquanto motivado pelo sentido percebido.

Chegamos, assim, à concepção propriamente merleau-pontiana do funcionamento nervoso em sua relação com o comportamento, concepção essa calcada em uma filosofia da forma, desenvolvida a partir das experiências da escola de Berlin, acrescida da ruptura em relação à ideia dessa mesma escola acerca do isomorfismo entre as formas psíquica, fisiológica e física. Segundo Merleau-Ponty, partindo dessa noção, a psicologia da forma mostra não ter reconhecido como necessária a reforma da concepção de conhecimento e de metafísica que se atrelava às próprias experiências que ela trazia à luz. Afinal, o isomorfismo terminava por assentar no mundo da física, segundo a tradição do materialismo, o sentido da percepção. Merleau-Ponty a todo instante frisa que, para que se possa compreender o fenômeno perceptivo, não há como deixar de reconhecer o primado do mundo percebido, não há como partir senão dos dados fenomenais, como veremos a seguir.

Uma forma, seja em um sistema físico ou em um sistema orgânico, adquire uma realidade própria. Com isso quer-se dizer que a forma não é a simples consequência da presença dos materiais que a compõem. Nela, os processos que ocorrem, quaisquer que sejam eles, configuram a ocasião para a formação de uma unidade indecomponível e que não pode ser apreendida pela soma de processos locais e parciais. A forma adquire 
propriedades originais em relação às suas partes. Cada momento da forma define-se pelo todo, o valor de cada uma das suas partes depende do estado de equilíbrio total. O sistema, a estrutura, gera suas próprias leis de equilíbrio e de funcionamento cuja fórmula é um fator intrínseco à própria forma.

Nesse sentido, a noção de forma possui qualidades que the possibilitam dar conta do funcionamento nervoso. Esse pode ser apreendido enquanto processo do tipo "figura e fundo", no qual a ambiguidade do lugar na substância nervosa parece encontrar uma significação. Tanto as localizações horizontais, ou seja, pontuais, quanto aquelas verticais, que dizem respeito a campos funcionais, podem ser compreendidos como "figuras" inseparáveis do fundo constituído pela atividade do todo da matéria nervosa.

Mas é importante sublinhar que é ao mundo fenomenal que recorremos quando utilizamos os termos "figura" e "fundo" para descrever as "formas fisiológicas". É somente no mundo percebido que a função "figura e fundo" encontra sentido. Portanto, pode-se afirmar que o percebido somente é acessível por meio do próprio percebido; falar de processos fisiológicos pretensamente puros no que tange à análise da percepção é impossível. Isso se coaduna com o fato de que, caminhando rumo ao centro do córtex cerebral, percebemos que as condições do comportamento encontram-se menos na substância nervosa do que nos "modos qualitativamente variáveis do seu funcionamento global" (Merleau-Ponty, 1942/2002, p. 102). É por isso que Merleau-Ponty atrela decisivamente a fisiologia ao pensamento psicológico no que diz respeito às relações do comportamento com o cérebro. Diz o autor: "A fisiologia não poderia ser pensada completamente sem empréstimo à psicologia" (p. 102). Sem o recurso ao percebido, a fisiologia do funcionamento nervoso não alcança senão abstrações que, em um momento ou em outro, revelam a sua infertilidade.

Em suma, o funcionamento nervoso não é concebível sem que se faça referência ao campo fenomenal e às suas leis de equilíbrio interior, ao mundo percebido e às suas estruturas próprias. Ele constitui um processo de forma, noção ela própria emprestada ao mundo fenomenal e fundamental para que compreendamos as relações do comportamento com o cérebro. Através dela, pensa-se em ultrapassar o atomismo nas concepções sobre o funcionamento nervoso sem reduzi-lo a uma atividade indiferenciada e, ainda, sem reduzir o próprio comportamento às funções nervosas, na medida em que estas não podem ser abstraídas do campo fenomenal ou do corpo enquanto ser no mundo; pensa-se, também, em ultrapassar o localizacionismo ou o materialismo no sentido estrito do termo, sem deslizar para a formulação de teses intelectualistas ou espiritualistas. 


\section{Considerações finais}

As teses materialistas acerca do problema mente-corpo possuem suas origens no dualismo cartesiano, agravado pelas disputas entre espiritualistas e realistas ao longo de três séculos. Tais teses apoiam-se na esperança no triunfo da ciência em sua pretensão de explicar todos os fenômenos que nos cercam. Sob esse viés materialista, parte da ciência espera dar conta de explicar o funcionamento cerebral e, consequentemente, de explicar as facetas do nosso funcionamento psicológico. Bergson, em uma espécie de fenomenologia do ato perceptivo, tentou suplantar a tese materialista. Mostrou que as hipóteses fisiológicas acerca dos fenômenos da percepção e da memória não desfazem a necessidade de que, em algum ponto, a consciência seja reconhecida, ou como um milagre, como um epifenômeno ou como um mero acaso. Todavia, as noções trabalhadas por Bergson deixam lacunas. A tese de que a percepção tem seu motivo na tendência de aderir aos interesses do ser vivo não deságua em uma espécie de vitalismo? Para Merleau-Ponty, Bergson articula uma noção de percepção, mas que não leva a consciência e a ação a um imbricamento verdadeiro em uma estrutura natural e, assim, o autor não escapa ao dualismo, o que o próprio Bergson reconhece, como vimos, na introdução de "Matéria e Memória". Já Merleau-Ponty apresenta-nos uma noção estrutural do funcionamento nervoso, fazendo brotar a consciência enquanto forma. $\mathrm{O}$ filósofo reafirma o cérebro como o "setor central" do comportamento, mas também, e com a mesma convicção e sustentação empírica, que as condições fisiológicas cerebrais não são suficientes para a sua compreensão. $O$ funcionamento nervoso de modo geral e, em um grau mais específico, a consciência perceptiva, exigem uma análise de caráter estrutural, pautada no campo fenomenal e no mundo percebido. Esperamos ter mostrado, ainda, que ambos escolheram desenvolver seus pensamentos em um mesmo campo da filosofia, o da questão mente-corpo, e com atitudes muito parecidas, sobretudo ao fazê-la dialogar com o conhecimento científico. Os projetos filosóficos de Bergson e de M-P convergem em suas investigações sobre a noção de experiência, sobretudo na medida em que ambos almejam liberá-la das determinações prévias advindas do senso comum, da ciência ou da própria reflexão filosófica. Acima de tudo, os dois autores recusam as soluções clássicas da filosofia moderna que se encontravam amalgamadas ao trabalho científico do seu tempo (Pinto, 2006). Bergson escreveu: "É preciso optar, em filosofia, entre o puro raciocínio que visa a um resultado definitivo, imperfectível, pois é suposto perfeito, e uma observação paciente que fornece apenas resultados aproximativos, capazes de ser corrigidos e completados indefinidamente" (Bergson, 1974b, p. 104). Bergson optou pelo segundo plano de ação e, sem dúvida, Merleau-Ponty fez o mesmo, dando continuidade e fazendo avançar as investigações do seu antecessor. 


\title{
Henri Bergson's and Maurice Merleau-Ponty's critique to the materialistic approaches to the mind-body problem
}

\begin{abstract}
In this paper we present Henri Bergson's and Maurice Merleau-Ponty's critique to the materialistic approaches to the mind-body problem. These approaches are intrinsically connected to the scientific aspirations, inaugurated with modernity, by encompassing all phenomena around us and of unifying the world's diversity in only one explaining pattern. In a kind of phenomenology of the perceptive act, Bergson tried to overcome the materialistic theses of the relationships between mind and brain. By attaining to the psychophysical parallelism, Bergson showed that perception answers to the needs of the living being. Besides, he approached the relationship between memory and brain, fighting the idea that recollections exhibit a nature such that permits they are stored in the brain mass. On the other hand, in The Structure of Behavior, after his critique of the classical conceptions of the nervous system functioning, and after considering the results of research presenting the brain as the coordinating entity of the behavioral structure, Merleau-Ponty presents his perspective based on the primacy of the perceived world, which in turn is based on the notion of form. We also discuss the philosophical heritage left by Bergson to Merleau-Ponty as well as some of latter's critiques to the former's work.
\end{abstract}

Keywords: Mind-body problem. Psychophysical parallelism. Bergson, Henri Louis, 1859-1941. Merleau-Ponty, Maurice, 1908-1961.

\section{Les critiques de Henri Bergson et de Maurice Merleau-Ponty aux conceptions materialistes du problème corps-esprit}

Résumé: Dans cet article, nous présentons les critiques de Henri Bergson et de Maurice Merleau-Ponty aux conceptions materialistes du problème corpsesprit. Tels conceptions sont, intrinsèquement, attachées aux ambitions scientifiques, inaugurées avec la modernité, de totaliser les phénomènes que nous entourent et d'unifier la diversité du monde par une norme explicatif unique. Bergson, dans une sorte de phénoménologie de l'acte perceptif, a essayé de surmonter les théses materialistes du rapport entre esprit et cerveau. En s'occupant du parallélisme psychophysiologique, il a montré que la perception répond aux nécessités de l'être vivant. D'ailleurs, il a abordé le rapport entre mémoire et cerveau, en refusant l'idée que les souvenirs possèdent une telle nature qui permette qu'elles soient emmagasinées dans la masse cérébral. D'autre part, Merleau-Ponty, dans "La Structure du Comportement ", après réaliser la critique des conceptions classiques du fonctionnement nerveux et après s'approprier des résultats de recherches que présentent le cerveau comme entité coordinatrice de la structure du comportement, il présent une vision du fonctionnement nerveux 
soutenue dans le primat du monde perçu à partir de la notion de forme. On discute, encore, les héritages philosophiques léguées par Bergson à Merleau-Ponty et quelques critiques de celui-ci à l'oeuvre de son prédécesseur.

Mots-clés: Problème corps-esprit. Parallélisme psychophysiologique. Bergson, Henri Louis, 1859-1941. Merleau-Ponty, Maurice, 1908-1961.

\section{Las críticas de Henri Bergson y Maurice Merleau-Ponty a los enfoques materialistas del problema mente-cuerpo}

Resumen: En este artículo se presentan las críticas de Henri Bergson y Maurice Merleau-Ponty a los enfoques materialistas del problema mentecuerpo. Tales enfoques están intrínsecamente vinculados a las ambiciones científicas, inauguradas con la modernidad, de totalizar los fenómenos que nos rodean y de unificar la diversidad del mundo por un solo patrón explicativo. Bergson, en una especie de fenomenología del acto perceptivo, intentó superar las teorías materialistas de la relación mente y cerebro. Acercándose del paralelismo psicofisiológico, mostró que la percepción se ocupa de las necesidades del ser vivo. Por otra parte, abordó la relación entre memoria y cerebro, rechazando la idea de que los recuerdos son de tal naturaleza que les permite ser almacenados en la masa cerebral. A su vez, Merleau-Ponty, en La Estructura del Comportamiento, después de hacer la crítica de conceptos clásicos del funcionamiento nervioso y utilizando los resultados de investigaciones que presentan el cerebro como entidad coordinadora de la estructura del comportamiento, presenta una visión del funcionamiento nervioso apoyado en la primacía del mundo percibido a través de la noción de forma. Discutimos además las herencias filosóficas legadas por Bergson a Merleau-Ponty y algunas críticas de este último al trabajo de su antecesor.

Palabras clave: Problema mente-cuerpo. Paralelismo psicofisiológico. Bergson, Henri Louis, 1859-1941. Merleau-Ponty, Maurice, 1908-1961.

\section{Referências}

Bergson, H. (1968). Matière et mémoire: essai sur la relation du corps a l'esprit (92a ed.). Paris: Presses Universitaires de France.

Bergson, H. (1974a). O cérebro e o pensamento: uma ilusão filosófica. In H. Bergson, Cartas, conferências e outros escritos (Coleção Os Pensadores). São Paulo: Abril Cultural.

Bergson, H. (1974b). A alma e o corpo. In H. Bergson, Cartas, conferências e outros escritos (Coleção Os Pensadores). São Paulo: Abril Cultural. 
Bimbenet, É. (2004). Nature et humanité: le probleme anthropologique dans l'ouvre de Merleau-Ponty. Paris: Vrin.

Descartes, R. (1992). La dioptrique. In G. Rodis-Lewis (Org.), Discours de la méthode suivi d'extraits de la Dioptrique, des Météores, de la Vie de Descartes par Baillet, du Monde, de l'homme et de Lettres. Paris: Flammarion. (Trabalho original publicado em 1636)

Descartes, R. (1992). Méditations métaphysiques. Paris: Flammarion. (Trabalho original publicado em 1641)

Furlan, R. (2006). Filosofia como "pensamento de contato". In D. C. M. Pinto \& R. V. Marques (Orgs.), A fenomenologia da experiência: horizontes filosóficos da obra de Merleau-Ponty (pp. 35-69). Goiânia: Editora da UFG.

Merleau-Ponty, M. (2000). A natureza. São Paulo: Martins Fontes.

Merleau-Ponty, M. (2002). La structure du comportement [A estrutura do comportamento]. Paris: Presses Universitaires de France. (Trabalho original publicado em 1942)

Pinto, D. C. M. (2006). A meditação segundo a percepção: Bergson, Merleau-Ponty e o verdadeiro sentido da experiência. In D. C. M. Pinto \& R. V. Marques (Orgs.), A fenomenologia da experiência: horizontes filosóficos da obra de Merleau-Ponty (pp. 171-202). Goiânia: Editora da UFG.

Danilo Saretta Verissimo, Doutorando na Faculdade de Filosofia, Ciências e Letras de Ribeirão Preto da Universidade de São Paulo, Bolsista CAPES. Endereço para correspondência: Rua General Rondon, 26, ap. 53, CEP 11030-570, Santos, SP. Endereço eletrônico: dsverissimo@pg.ffclrp.usp.br

Reinaldo Furlan, Professor da Faculdade de Filosofia, Ciências e Letras de Ribeirão Preto da Universidade de São Paulo. Endereço para correspondência: Av. Bandeirantes, 3900, CEP 14040-901, Ribeirão Preto, SP. Endereço eletrônico: reinaldof@ffclrp.usp.br

Recebido em: 13/07/2008

Aceito em: 24/09/2008 